\title{
WAVE-FLUME EXPERIMENTS OF DISSIPATING WAVES ON SOFT MUD
}

\author{
Mohsen Soltanpour ${ }^{1}$, Farzin Samsami² and Soroush Sorourian ${ }^{3}$
}

\begin{abstract}
A series of laboratory wave-flume experiments was conducted to investigate the dissipation of monochromatic regular waves on a horizontal muddy bed of commercial kaolinite. The rheological parameters of kaolinite samples with different water content ratios were obtained from controlled shear rate tests using the rheometer. The flow curves of shear stress versus shear rate were found to be essentially Bingham viscoplastic medium for steady unidirectional mud flows of the rheological tests. Assuming Bingham behavior for kaolinite, a wave-mud interaction model was employed to obtain the values of the wave attenuation coefficients. Comparisons between the measured and simulated results show a good agreement.
\end{abstract}

Keywords: wave dissipation, rheological model, fluid mud, kaolinite, wave flume experiment, rheometry experiment

\section{INTRODUCTION}

Although typical muddy coasts are not too common, they can be found in many coastal areas of the world, normally adjacent to big rivers. Some typical examples of mud coasts are Ariake Sea in Japan, West coast of Peninsular Malaysia, Louisiana East Bay in the United States and North-West of the Persian Gulf in Iran. Fig. 1 shows muddy coasts located at the Persian Gulf.

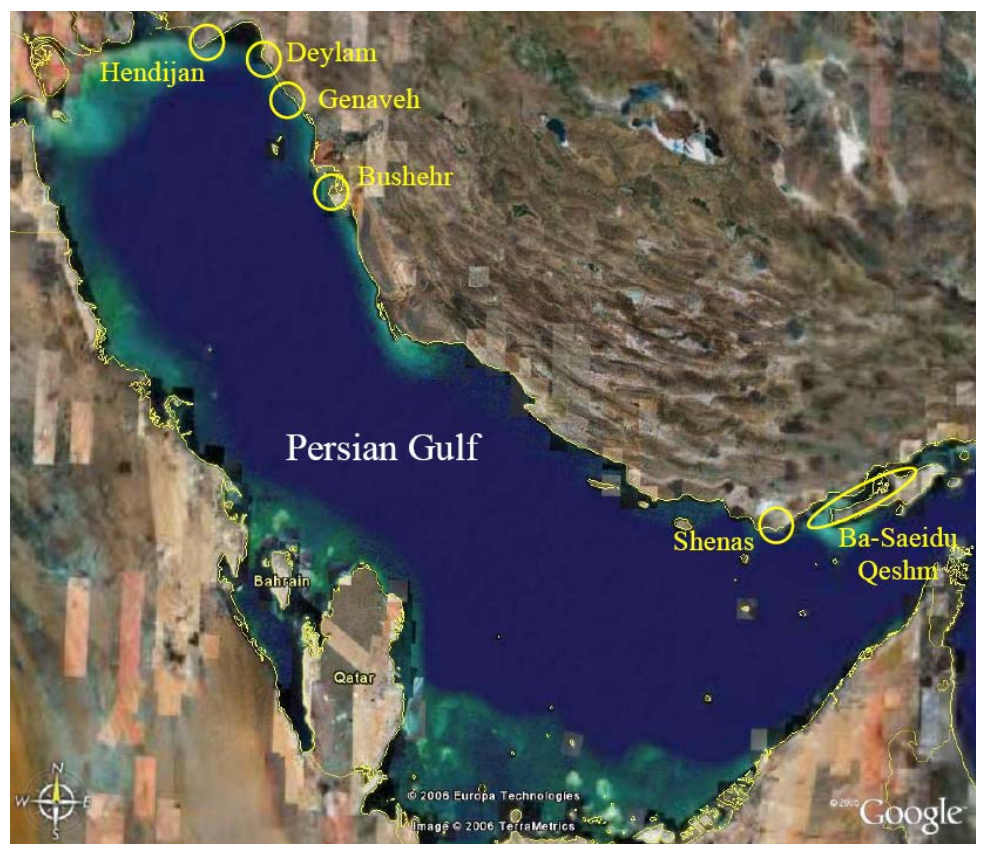

Figure 1. Location of muddy coasts at the Persian Gulf

Water waves propagating over a muddy bed are attenuated mainly due to the energy dissipation in mud layers. Fishermen as well as coastal engineers are aware of the basic role played by mud flats in dissipating the energy of propagating waves in coastal areas. Gade (1958) noted a region of mud located in the offshore of the central Louisiana coast, known as the mud hole, where the attenuation of waves due to the mud bottom is so considerable that it is used as an emergency harbor by fishing boats during storms. Engineering interest has also grown in creating offshore under water berms that can dissipate wave energy by beneficially using dredged fine-grained material from navigation channels (McLellan et al. 1990).

The attenuation of wave height on a horizontal bed is usually approximated by an exponential function:

\footnotetext{
${ }_{1}^{1}$ Department of Civil Engineering, K. N. Toosi University of Technology, No. 1346, Vali-Asr St., Tehran 19967, Iran

2 Department of Civil Engineering, K. N. Toosi University of Technology, No. 1346, Vali-Asr St., Tehran 19967, Iran

${ }^{3}$ Darya Bandar Consulting Engineers, No. 9, Zabety Ave., Heravi Sq., Pasdaran, Tehran 16677, Iran
} 


$$
H(x)=H_{0} e^{-k_{i} x}
$$

where $H_{0}$ is the incident wave height at $x=0$ and $k_{i}$ is the wave attenuation coefficient. Eq. 1 has the support of both theoretical and laboratory investigations (eg. Keulegan 1950; Gade 1958; Iwasaki and Sato 1972; Dalrymple and Liu 1978; Maa and Mehta 1990). Moreover, the variety of applied rheological models by the researchers shows that the reliability of the exponential decay approximation is not related to the assumed rheological behavior.

Conducting a series of wave-flume laboratory experiments on commercial kaolinite, the wave height attenuation is studied in the present study. The laboratory results are also compared with a developed wave-mud interaction numerical model.

\section{RHEOLOGICAL MODEL}

Viscometer measurements have shown that clay suspensions in the fluid mud range behave as plastic solids, characterized by a capacity to resist deformation up to some critical level of imposed shear stress (eg. Bingham 1922; Tsuruya et al. 1986). The simplest constitutive model for these viscoplastic materials is the Bingham fluid model in which the excess stress is linearly proportional to the shear rate. The constitutive equation for the case of simple shear can be written as follows

$$
\tau=\tau_{y} \operatorname{sign} \frac{\partial u}{\partial z}+\mu_{m} \frac{\partial u}{\partial z} \quad \text { if } \quad|\tau|>\tau_{y}
$$

where $\tau_{y}$ is the yield stress, $\mu_{m}$ is the Bingham viscosity and $u$ is the velocity in $x$ direction.

There are some difficulties in applying the Bingham fluid model to the wave-mud interaction problems as the critical shear stress level, i.e. yield point, is an unknown function of space and time. Considering the continuous motion of mobile mud, some researchers have introduced a so-called "equivalent viscosity" to convert the Bingham fluid model into the viscous fluid model. Tsuruya et al. (1987) used the equivalent viscosity defined as

$$
\mu_{e}=\mu_{m}+\frac{\tau_{y}}{\sqrt{4\left|\Pi_{e}\right|}}
$$

where $|\Pi|_{e}$ is the objective of the strain rate tensor expressed as

$$
\left|\Pi_{e}\right|=\frac{1}{2}\left(\dot{e}_{1}^{2}+\dot{e}_{2}^{2}\right)+\dot{e}_{12}^{2}
$$

where $\dot{e}_{i j}$ is the deviator part of strain rate tensor. As $|\Pi|_{e}$ depends on the motion of fluid, the timeaveraged value at the initial location $x=0$ was used. As the first approximation, due to the difficulties concerning direct estimation of velocity field from the rheological equations, they estimated the velocity field for Newtonian fluids and calculated the equivalent viscosity from it. Again the velocity field was calculated by using the newly estimated viscosity and the iterative calculations were repeated until the solutions converged.

Commercial kaolinite was used as bed sediment in the experiments of this study due to its similar rheological behavior with natural mud and its easy handling. The distribution of particle sizes of the kaolinite passes through the points $D_{45}=2 \mu \mathrm{m}$ and $D_{99}=20 \mu \mathrm{m}$. Its chemical composition is comprised with $61-62 \%$ of $\mathrm{SiO}_{2}, 24-25 \%$ of $\mathrm{AL}_{2} \mathrm{O}_{3}$, and $0.45-0.65 \%$ of $\mathrm{Fe}_{2} \mathrm{O}_{3}$.

The visco-plastic parameters of applied kaolinite were extracted from the rheometry experiments. The experiments were conducted at the Rheometery Laboratory of Institute for Colorants, Paint and Coatings (ICPC) using an Anton Paar Physica MCR300 instrument in rotational mode. Fig. 2 shows the yield stress and viscosity versus shear strain rate of kaolinite sample with various water content ratios. Fig. 3 represents the high correlation of visco-plastic parameters, i.e. $\mu_{m}$ and $\tau_{y}$, versus water content ratios of kaolinite samples. 


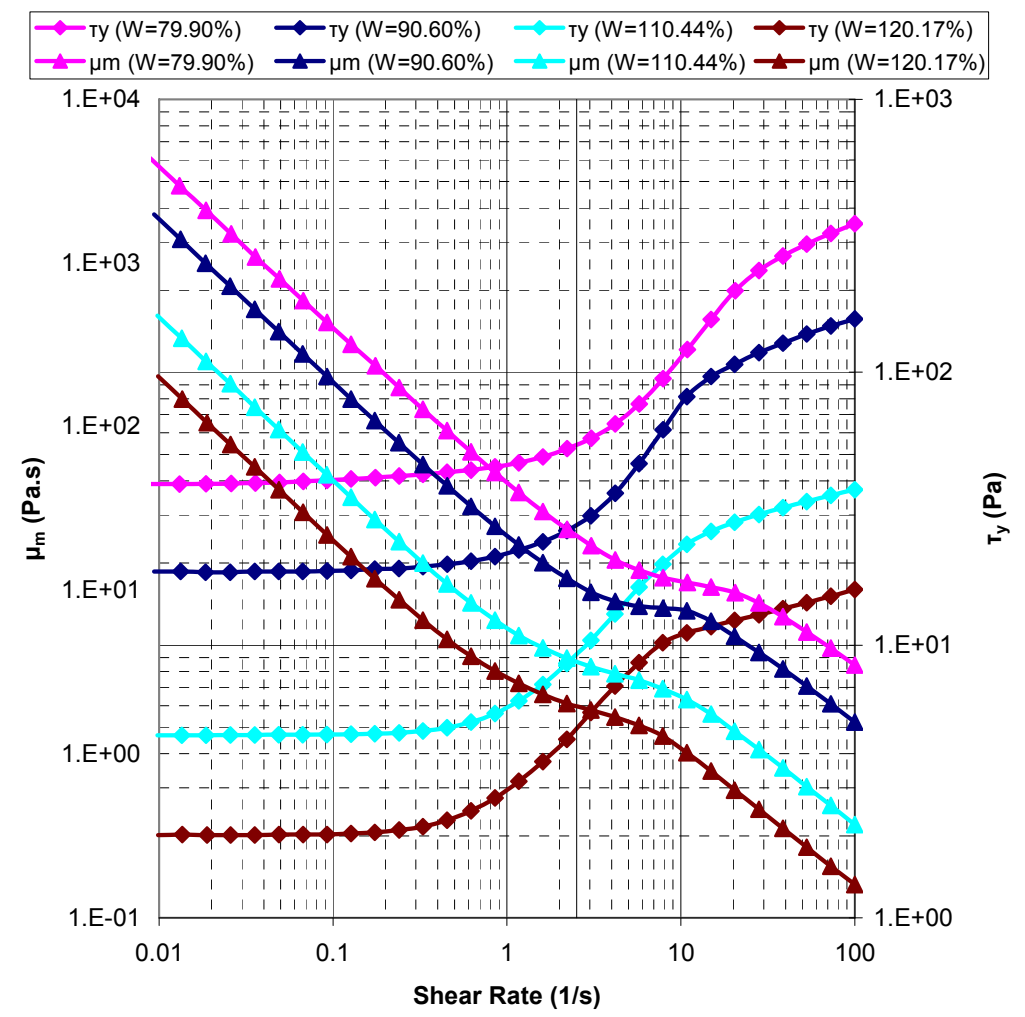

Figure 2. Measured visco-plastic rheological parameters of kaolinite

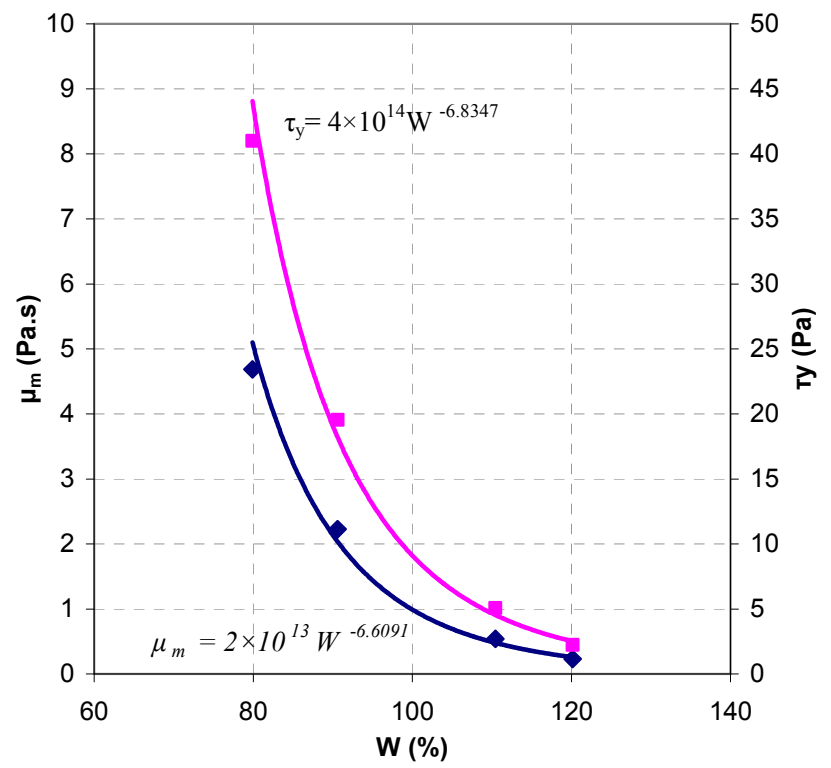

Figure 3. Visco-plastic rheological parameters versus water content

\section{WAVE-MUD INTERACTION MODEL}

A developed wave-mud interaction model is used to simulate the wave height attenuation. Following Tsuruya et al. (1987), the fluid system, including the water layer and fluid mud layer, is divided into $N$ sub-layers, in which the water layer is represented by $N=1$ (Fig. 4). 


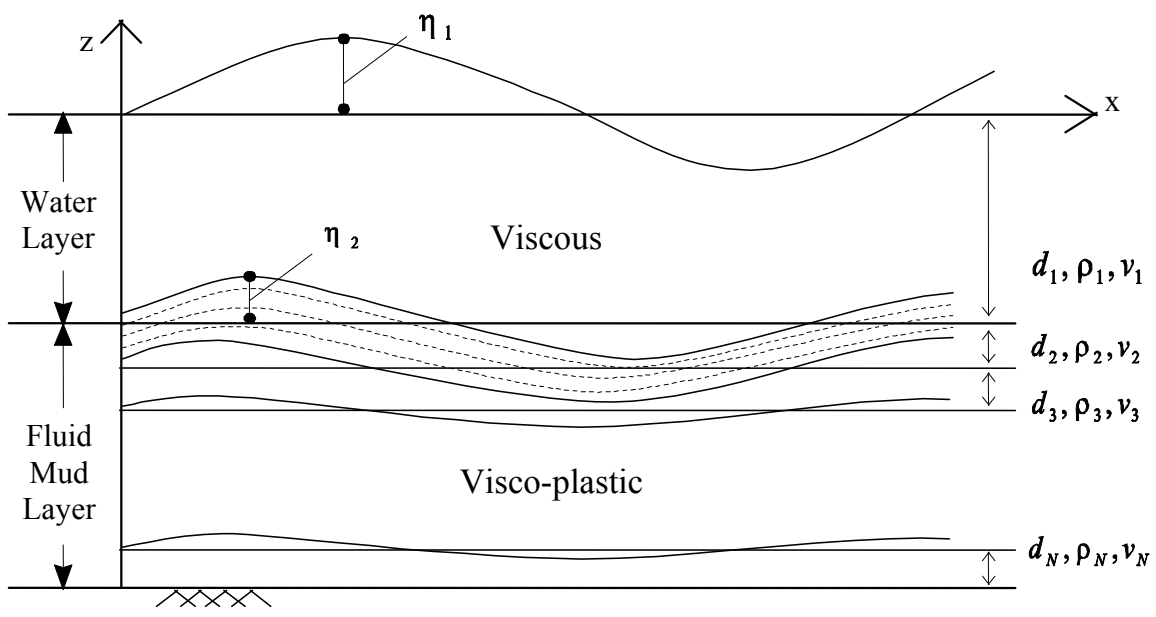

Figure 4. Multi-layered wave-fluid mud interaction model

The governing equations are the linearized Navier-Stokes equations, neglecting the convective accelerations, and the continuity equation

$$
\begin{gathered}
\frac{\partial u_{j}}{\partial t}=-\frac{1}{\rho_{j}} \frac{\partial p_{j}}{\partial x}+v_{e, j}\left(\frac{\partial^{2} u_{j}}{\partial x^{2}}+\frac{\partial^{2} u_{j}}{\partial z^{2}}\right) \\
\frac{\partial w_{j}}{\partial t}=-\frac{1}{\rho_{j}} \frac{\partial p_{j}}{\partial z}+v_{e, j}\left(\frac{\partial^{2} w_{j}}{\partial x^{2}}+\frac{\partial^{2} w_{j}}{\partial z^{2}}\right) \\
\frac{\partial u_{j}}{\partial x}+\frac{\partial w_{j}}{\partial z}=0
\end{gathered}
$$

where $x$ and $z$ are the horizontal and vertical coordinates, $u$ and $w$ are the horizontal and vertical components of orbital velocity, the subscripts $j$ indicate the layers, and the parameters $t, \rho, v_{e}$ and $p$ represent the time, density, equivalent viscosity of mud and dynamic pressure, respectively. Allocating a constant viscosity to each fluid mud sub-layer by a repetitive method, the simplified visco-plastic model can be introduced to Navier-Stokes equations to describe the rheological parameters of fluid mud layer.

The periodic solutions for $\hat{u}_{j}, \hat{w}_{j}, \hat{p}_{j}$ are assumed as

$$
\begin{aligned}
& \hat{u}_{j}(x, z ; t)=u_{j}(z) \exp [i(k x-\omega t)] \\
& \hat{w}_{j}(x, z ; t)=w_{j}(z) \exp [i(k x-\omega t)] \\
& \hat{p}_{j}(x, z ; t)=p_{j}(z) \exp [i(k x-\omega t)]
\end{aligned}
$$

where $\omega$ is the wave angular frequency and $k$ is the unknown complex wave number

$$
k=k_{r}+i k_{i}
$$

The real part represents the wave number and the imaginary part presents the wave damping coefficient, assuming the exponential wave height decay. Displacements of water surface and interfaces, $\eta_{j}$ are assumed as

$$
\eta_{j}=a_{j} \exp [i(k x-\omega t)]
$$


where $a_{j}$ is the displacement amplitude of the $j$-th sub-layer and the water surface is expressed as $\eta_{1}$. Substituting the real and imaginary parts of wave number into Eq. 12, the expression of water surface and interfacial displacements can be obtained as

$$
\eta_{j}=a_{j} \exp \left(-k_{i} x\right) \exp \left[i\left(k_{r} x-\omega t\right)\right]
$$

The above system of equations is solved considering the boundary conditions. $5 \mathrm{~N}$ boundary conditions are needed for a fluid system of $\mathrm{N}$ sub-layers including water layer, as presented by Tsuruya et al. (1987). The kinematic boundary conditions are the continuity of horizontal and vertical velocities at interfaces and zero horizontal and vertical velocities at the rigid bottom. The imposition of zero normal and tangential stresses at the water surface and the continuity of normal and tangential stresses across the interfaces offer the required dynamic boundary conditions. The wave attenuation rate, $k_{i}$ is calculated by this model.

\section{LABORATORY INVESTIGATIONS}

The experiments were carried out in the wave flume of Hydraulic Models Laboratory of K. N. Toosi University of Technology. Fig. 5 shows the sketch of the experimental setup. The wave flume is $0.30 \mathrm{~m}$ wide and $0.50 \mathrm{~m}$ deep in cross-section and $12.5 \mathrm{~m}$ in length. It can be visually examined through its toughened glass sidewalls.

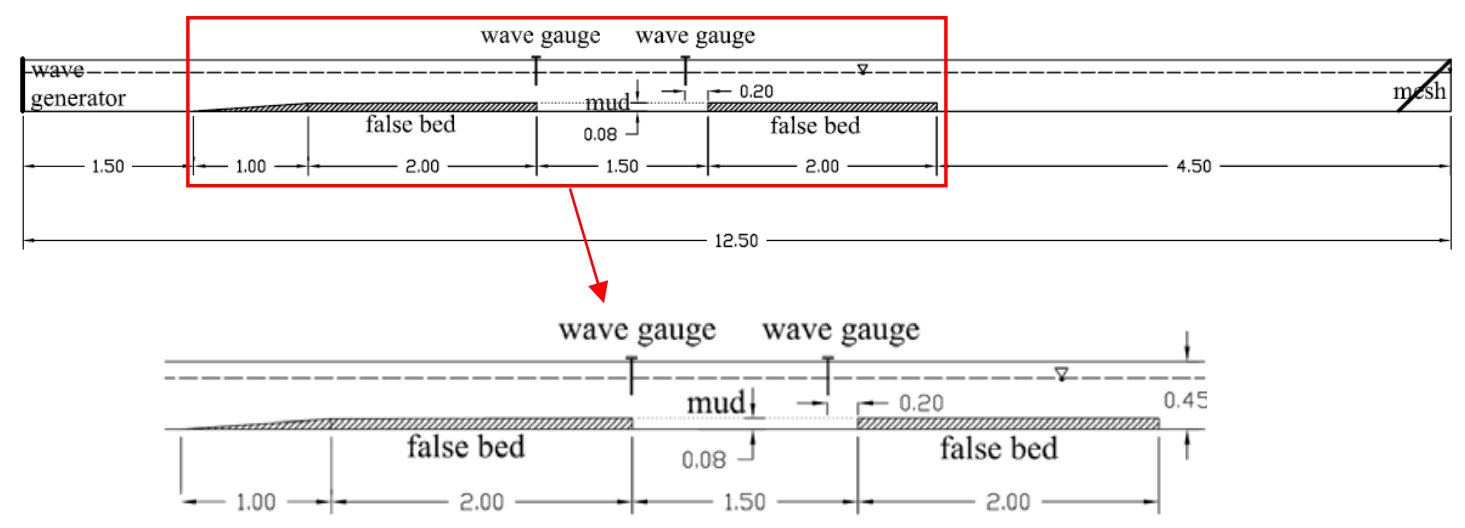

Figure 5. Sketch of experimental setup, units in $\mathrm{m}$

The monochromatic waves were produced by an electrically driven piston machine with a paddle at the beginning of the flume. The operating paddle is able to produce both regular and irregular waves. Adjusting the stroke and the speed of motor, different wave frequencies and wave amplitudes can be produced. Two electric capacitance wave gauges were employed to examine the wave height attenuation along the flume. Wave heights were recorded at two stations located $1.3 \mathrm{~m}$ apart where the first gauges measured the incident wave height at the beginning of mud layer. A false bed was placed in the flume to confine the mud section.

A well mixture of commercial kaolinite and tab water with $100 \%$ water content ratio was put in a 1.5 meter mud section with a constant thickness of $8 \mathrm{~cm}$. The duration time of generating waves can not be adopted very short since the effects of inertial force and thixotropy will become large. Table 1 shows the summary of test conditions of laboratory experiments.

\section{DISCUSSION}

Comparing the results of the numerical simulation with the current laboratory data, the capability of the numerical model is examined in this section. The mud bed was divided to 10 sub-layers in numerical model. Plastic viscosity and yield stress of kaolinite were selected from conducted rheological tests (Fig. 3). Table 1 also presents the measured and simulated wave attenuated results.

Figs. 6, 7, 8, 9 and 10 represent the comparisons between the measured and simulated wave attenuation coefficients versus wave heights for wave periods of $0.7,0.8,1.1,1.2$, and 1.4 seconds, respectively. The results of the numerical model generally agree with the measured results in spite of the existing discrepancies. It is also observed that the wave attenuation coefficients are slightly enhanced by the increase of wave heights. 


\begin{tabular}{|c|c|c|c|c|c|}
\hline Run & $\begin{array}{l}\text { Wave } \\
\text { period } \\
\text { (sec) }\end{array}$ & $\begin{array}{l}\text { Incident wave } \\
\text { height }(\mathrm{cm})\end{array}$ & $\begin{array}{l}\text { Attenuated wave } \\
\text { height }(\mathrm{cm})\end{array}$ & $\begin{array}{c}\text { Measured wave } \\
\text { attenuation } \\
\text { coefficient }(1 / \mathrm{m})\end{array}$ & $\begin{array}{l}\text { Simulated wave } \\
\text { attenuation } \\
\text { coefficient }(1 / \mathrm{m})\end{array}$ \\
\hline TG0 & 0.7 & 9 & 8.03 & 0.087723 & 0.0692 \\
\hline TG1 & 0.7 & 6.56 & 5.85 & 0.088115 & 0.0552 \\
\hline TG2 & 0.7 & 5.66 & 5.13 & 0.075629 & 0.0509 \\
\hline TG3 & 0.7 & 5.1 & 4.66 & 0.069404 & 0.0474 \\
\hline TG4 & 0.7 & 4.43 & 4.03 & 0.072795 & 0.0398 \\
\hline $\mathrm{THO}$ & 0.8 & 8.26 & 7.36 & 0.088742 & 0.111 \\
\hline $\mathrm{TH} 1$ & 0.8 & 7.13 & 6.23 & 0.103796 & 0.0982 \\
\hline $\mathrm{TH} 2$ & 0.8 & 6.83 & 5.9 & 0.112594 & 0.0961 \\
\hline TH3 & 0.8 & 6.13 & 5.43 & 0.093274 & 0.0923 \\
\hline $\mathrm{TH} 4$ & 0.8 & 5.56 & 4.93 & 0.092507 & 0.0886 \\
\hline TH5 & 0.8 & 5.2 & 4.55 & 0.102716 & 0.0857 \\
\hline TAO & 1.1 & 11 & 8.66 & 0.183985 & 0.135 \\
\hline TA1 & 1.1 & 8.93 & 7.4 & 0.144566 & 0.13 \\
\hline TA2 & 1.1 & 8.1 & 7.03 & 0.108983 & 0.128 \\
\hline TA3 & 1.1 & 7.46 & 6.35 & 0.123924 & 0.126 \\
\hline TA4 & 1.1 & 6.83 & 5.76 & 0.131067 & 0.123 \\
\hline TA5 & 1.1 & 5.46 & 5 & 0.087007 & 0.115 \\
\hline TD0 & 1.2 & 9.5 & 8.2 & 0.113198 & 0.124 \\
\hline TD1 & 1.2 & 7.13 & 6.26 & 0.100101 & 0.117 \\
\hline TD2 & 1.2 & 6.5 & 5.8 & 0.087649 & 0.115 \\
\hline TD3 & 1.2 & 6.2 & 5.46 & 0.09777 & 0.113 \\
\hline TD4 & 1.2 & 5.93 & 5.33 & 0.082056 & 0.112 \\
\hline TD5 & 1.2 & 5.16 & 4.6 & 0.088369 & 0.107 \\
\hline TFO & 1.4 & 7.67 & 6.4 & 0.139245 & 0.103 \\
\hline TF1 & 1.4 & 6.83 & 6.06 & 0.092011 & 0.0996 \\
\hline TF2 & 1.4 & 5.8 & 5.23 & 0.079574 & 0.0949 \\
\hline TF3 & 1.4 & 4.83 & 4.56 & 0.044249 & 0.0882 \\
\hline TF4 & 1.4 & 5 & 4.4 & 0.098333 & 0.0896 \\
\hline
\end{tabular}

Fig. 11 shows the comparison between all measured and simulated wave attenuation coefficients. Although the laboratory limitations and the simplifications of the numerical simulation affect the results, it is observed that the wave height attenuation can be predicted by the numerical model.

\section{SUMMARY AND CONCLUSION}

A number of wave-flume experiments were conducted to investigate wave energy dissipation on commercial kaolinite. The results show that the exponential wave height decay is a good approximation for the wave height decay over mud layer. This is in agreement with the findings of other researchers. It is also observed that the wave attenuation rates slightly increase by the wave heights increment. 


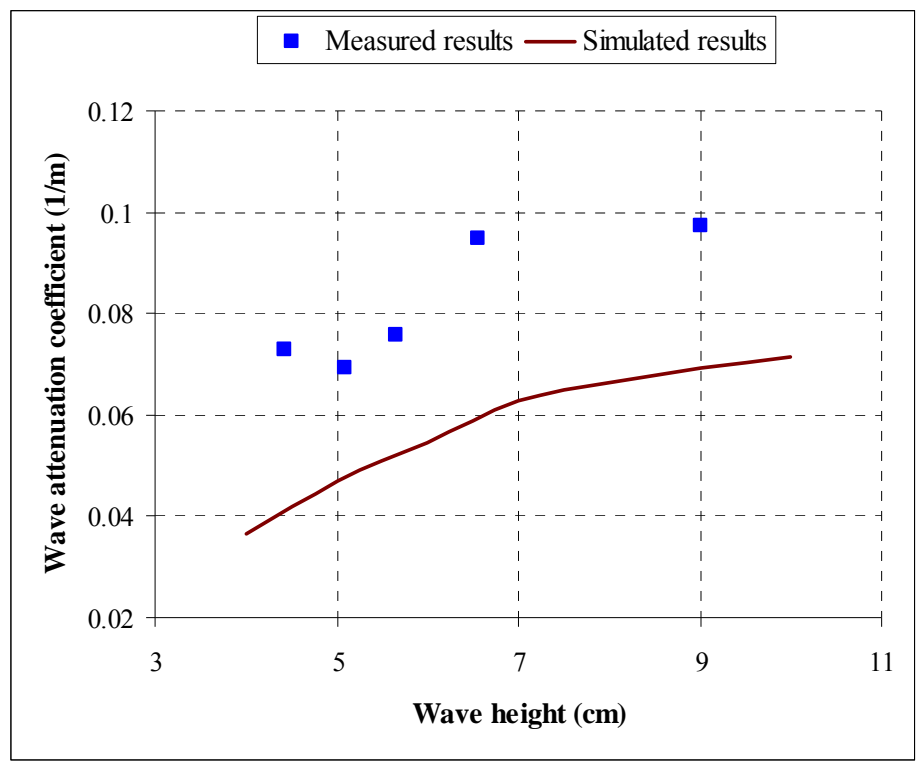

Figure 6. Wave attenuation coefficient versus incident wave height (wave period=0.7 sec)

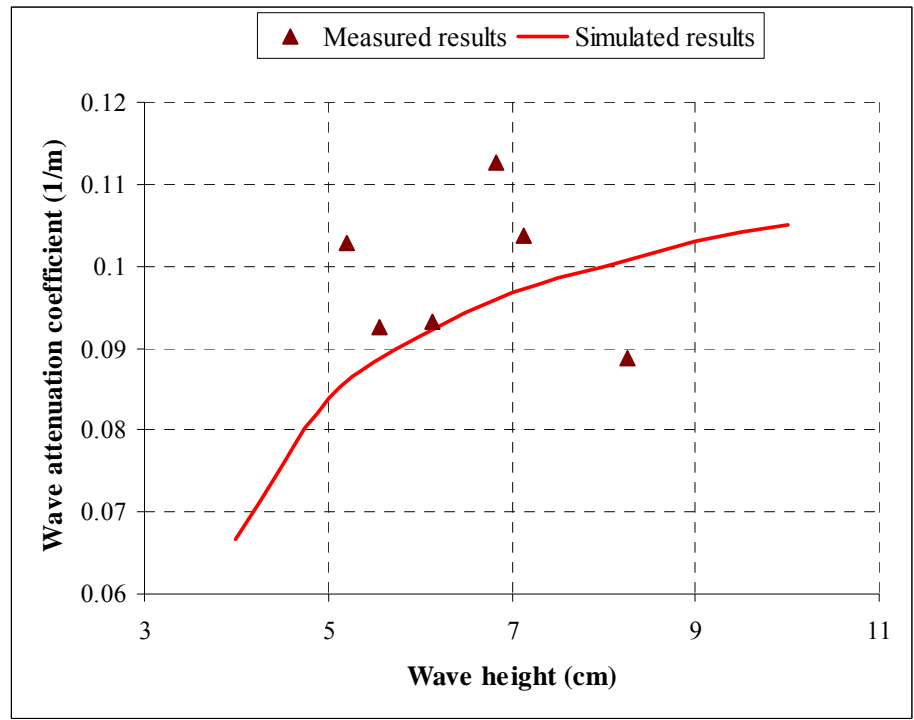

Figure 7. Wave attenuation coefficient versus incident wave height (wave period $=0.8 \mathrm{sec}$ ) 


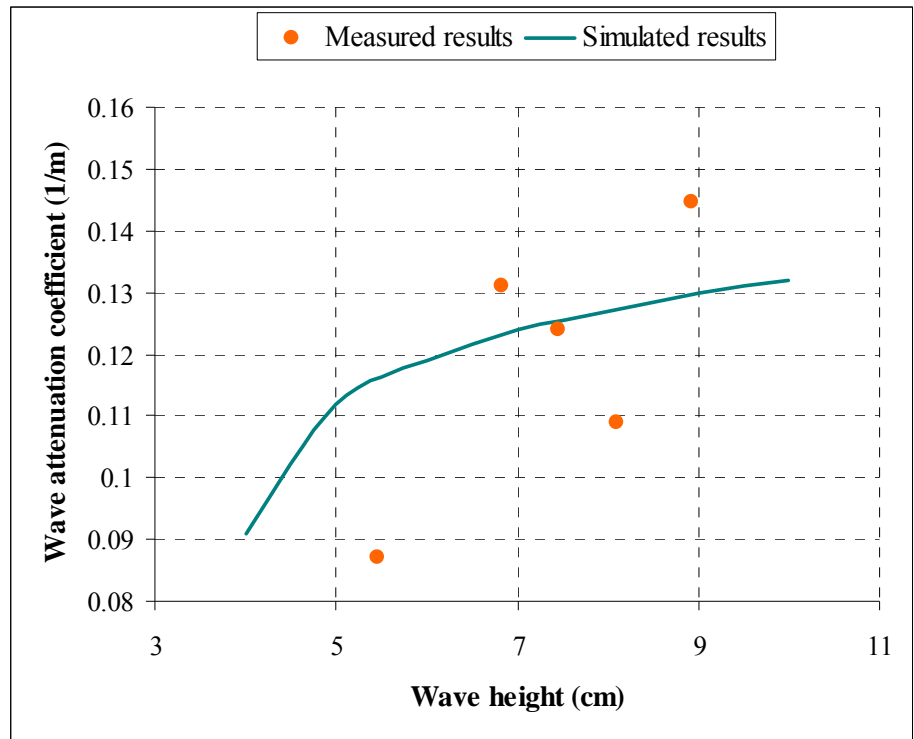

Figure 8. Wave attenuation coefficient versus incident wave height (wave period=1.1 sec)

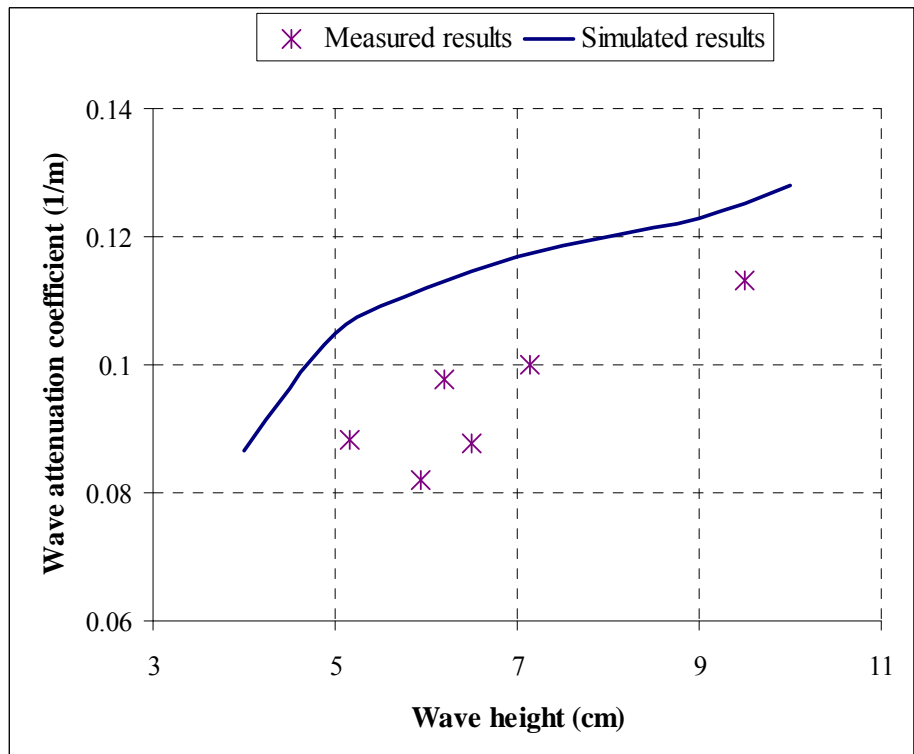

Figure 9. Wave attenuation coefficient versus incident wave height (wave period=1.2 sec) 


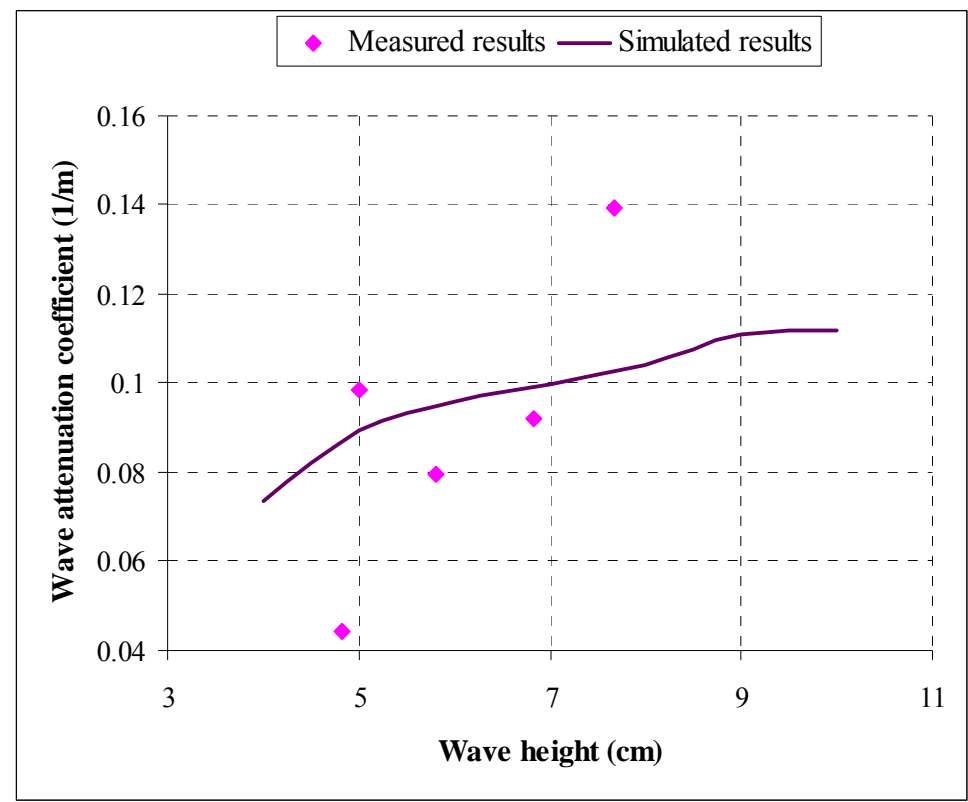

Figure 10. Wave attenuation coefficient versus incident wave height (wave period=1.4 sec)

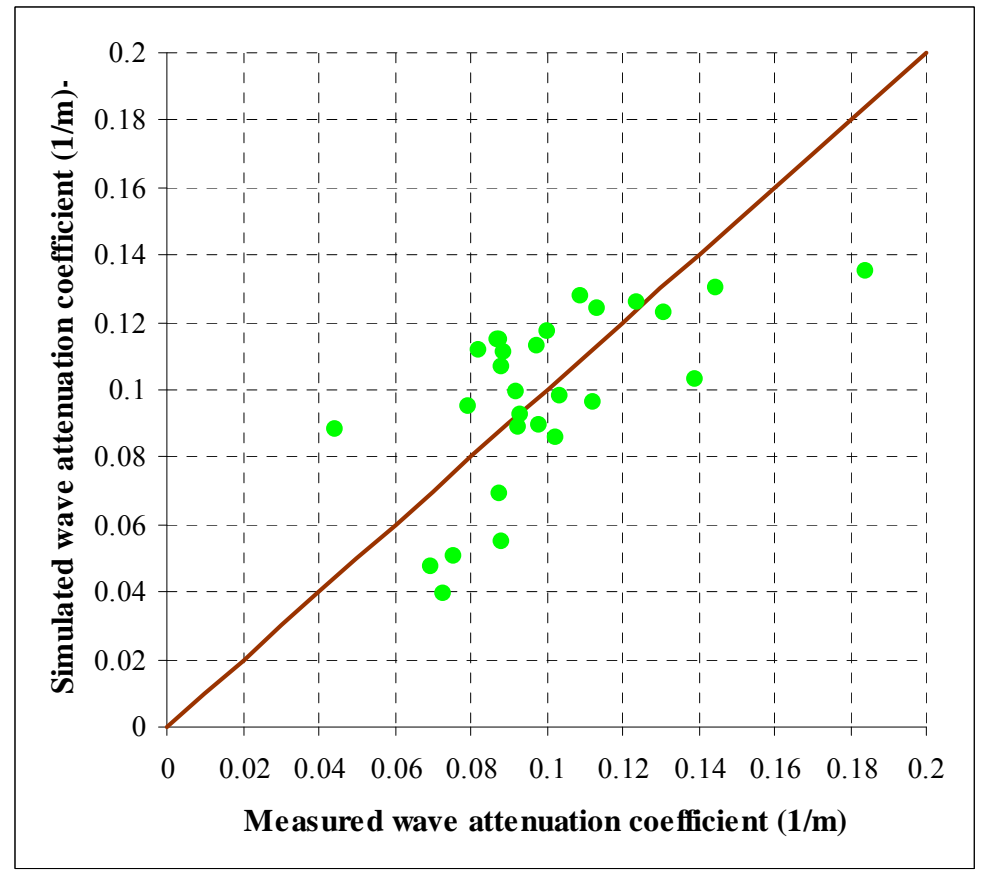

Figure 11. Comparison between the measured and simulated wave attenuation coefficients $(1 / \mathrm{m})$

\section{REFERENCES}

Bingham, E. C., 1922. Fluidity and plasticity, McGraw-Hill, 440 pp.

Dalrymple, R. A., and Liu, P. L.-f., 1978. Waves over muds, a two-layer fluid model. Journal Physical Oceanography, 8: 1121-1131.

Gade, H. G., 1958. Effects of non rigid, impermeable bottom on plane surface wave in shallow water. Journal of Marine Research, 16(2): 61-82.

Iwasaki, T., Sato, M., 1972. Dissipation of wave energy due to opposing current. Proceeding of $13^{\text {th }}$ Coastal Engineering Conference, ASCE, 1: 605-622. 
Keulegan, G. H., 1950. Wave Motion, Engineering Hydraulics. Chapter 11, John Wiley and Sons Inc., New York.

Maa, P.-Y. and Mehta, A. J., 1990. Soft mud response to water waves. Journal of Waterway, Port, Coastal and Ocean Engineering, ASCE, 116(5): 634-650.

McLellan, T.N.; Pope, M.K., and Burke, C.E., 1990. Benefits of nearshore placement. Proceedings of third annual technical conference, Florida Shore and Beach Preservation Association, Tallahassee, FL, pp 339-353.

Soltanpour, M., 1998. Two Dimensional Modeling of Mud Profile Processes. Ph.D. dissertation, Dept. of Civil Eng., Yokohama National University, Yokohama.

Tsuruya, H., Nakano, S., and Takahama, J., 1986. Investigation of rheological properties of soft muds with a rotary viscometer, Technical Note of Port and Harbor Research Institute, Ministry of Transport, Japan, No. 566, 29 pp. (in Japanese).

Tsuruya, H., Nakano, S., and Takahama, J., 1987. Interaction between surface waves and a multilayered mud bed. Report of Port and Harbor Research Institute, Ministry of Transport, Japan, 26(5): 138-173. 